This item was submitted to Loughborough's Research Repository by the author.

Items in Figshare are protected by copyright, with all rights reserved, unless otherwise indicated.

\title{
Fracture toughness of a zirconia engineering ceramic and the effects thereon of surface processing with fibre laser radiation
}

\section{PLEASE CITE THE PUBLISHED VERSION}

http://dx.doi.org/10.1243/09544054JEM1887

PUBLISHER

Sage / @ IMECHE

VERSION

VoR (Version of Record)

\section{LICENCE}

CC BY-NC-ND 4.0

\section{REPOSITORY RECORD}

Shukla, Pratik P., Jonathan Lawrence, and Houzheng Wu. 2019. "Fracture Toughness of a Zirconia Engineering Ceramic and the Effects Thereon of Surface Processing with Fibre Laser Radiation”. figshare. https://hdl.handle.net/2134/7667. 
This item was submitted to Loughborough's Institutional Repository (https://dspace.lboro.ac.uk/) by the author and is made available under the following Creative Commons Licence conditions.

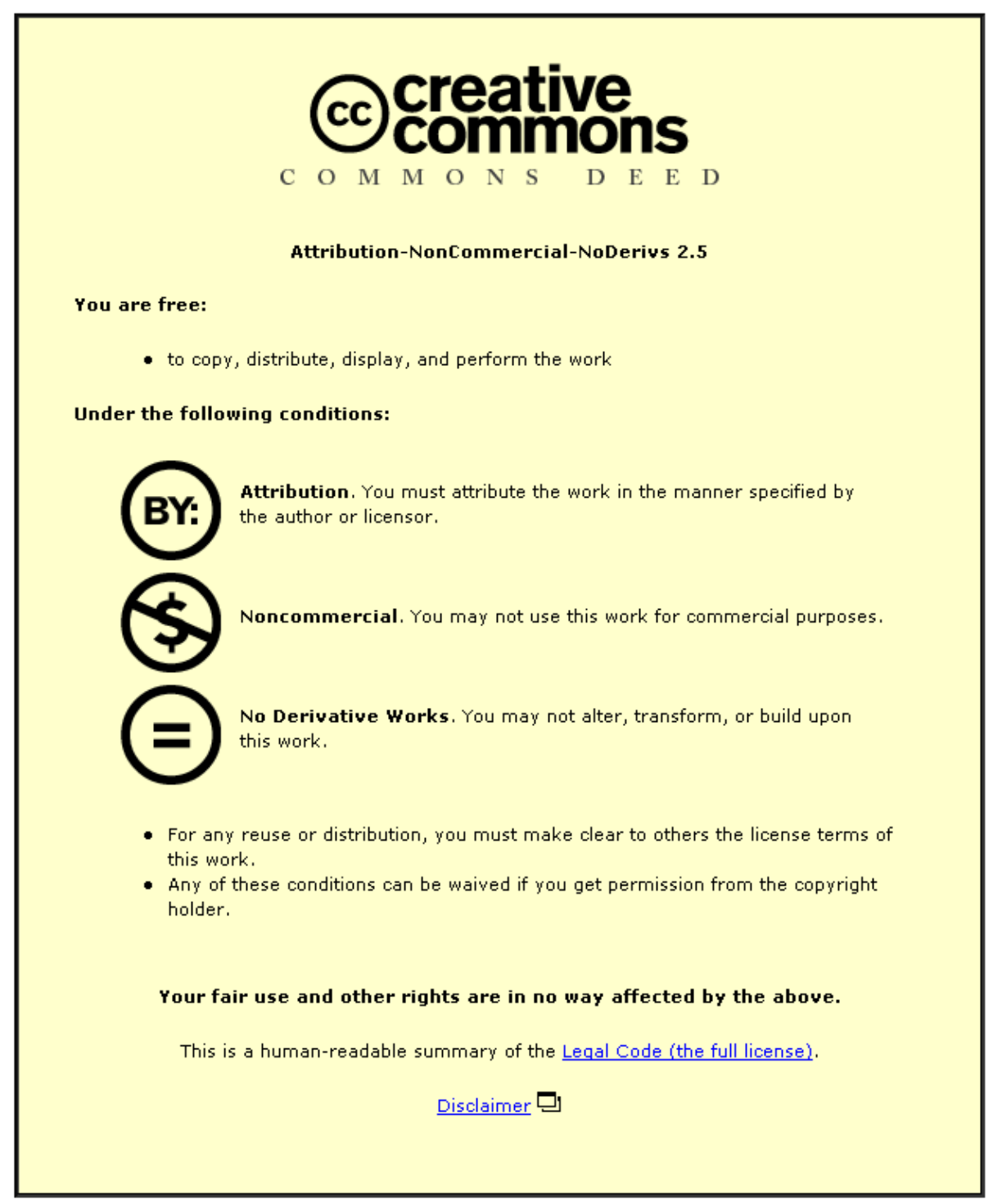

For the full text of this licence, please go to: http://creativecommons.org/licenses/by-nc-nd/2.5/ 


\title{
Fracture toughness of a zirconia engineering ceramic and the effects thereon of surface processing with fibre laser radiation
}

\author{
P P Shukla ${ }^{1 *}$, J Lawrence ${ }^{1}$, and $\mathrm{H} \mathrm{Wu}^{2}$ \\ ${ }^{1}$ Wolfson School of Mechanical and Manufacturing Engineering, Loughborough University, Loughborough, UK \\ ${ }^{2}$ Department of Materials, Loughborough University, Loughborough, UK
}

The manuscript was received on 4 November 2009 and was accepted after revision for publication on 27 January 2010.

DOI: 10.1243/09544054JEM1887

\begin{abstract}
Vickers hardness indentation tests were employed to investigate the near-surface changes in the hardness of a fibre laser-treated and an as-received $\mathrm{ZrO}_{2}$ engineering ceramic. Indents were created using 5, 20, and $30 \mathrm{~kg}$ loads to obtain the hardness. Optical microscopy, white-light interferometry, and a coordinate measuring machine were then used to observe the crack lengths and crack geometry. Palmqvist and half-penny median crack profiles were found, which dictated the selection of the group of equations used herein. Computational and analytical approaches were then adapted to determine the $K_{1 c}$ of $\mathrm{ZrO}_{2}$. It was found that the best applicable equation was: $K_{1 c}=0.016(E / H)^{1 / 2}\left(P / c^{3 / 2}\right)$, which was confirmed to be 42 per cent accurate in producing $K_{1 c}$ values within the range of 8 to $12 \mathrm{MPam}^{1 / 2}$ for $\mathrm{ZrO}_{2}$. Fibre laser surface treatment reduced the surface hardness and produced smaller crack lengths in comparison with the as-received surface. The surface crack lengths, hardness, and indentation loads were found to be important, particularly the crack length, which significantly influenced the end $K_{1 c}$ value when $K_{1 c}=0.016(E / H)^{1 / 2}\left(P / c^{3 / 2}\right)$ was used. This is because, the longer the crack lengths, the lower the ceramic's resistance to indentation. This, in turn, increased the end $K_{1 c}$ value. Also, the hardness influences the $K_{1 c}$, and a softer surface was produced by the fibre laser treatment; this resulted in higher resistance to crack propagation and enhanced the ceramic's $K_{1 c}$. Increasing the indentation load also varied the end $K_{1 c}$ value, as higher indentation loads resulted in a bigger diamond footprint, and the ceramic exhibited longer crack lengths.
\end{abstract}

Keywords: fracture toughness $\left(K_{1 c}\right)$, Vickers indentation technique, $\mathrm{ZrO}_{2}$ engineering ceramics

\section{INTRODUCTION}

Applications of ceramics have been limited owing to their crack sensitivity and low fracture toughness $\left(K_{1 c}\right)$. Nevertheless, the use of ceramics has increased over the years. They are now considered to be newage materials, used to manufacture components for the aerospace, automotive, military, and powergeneration sectors. Engineering ceramics offer exceptional mechanical properties, which allows them to replace the more conventional materials

*Corresponding author: Optical Engineering, Wolfson School of Mechanical and Manufacturing Engineering, Loughborough University, Loughborough LE11 3TU, UK.

email: pratik.shukla@talk21.com currently used for high-demanding applications. The engineering applications of various advanced ceramics have been amply demonstrated [1-7]. The Vickers indentation method, applicable for calculating the $K_{1 c}$ of the $\mathrm{Si}_{3} \mathrm{~N}_{4}$ ceramic, has been employed by Shukla [8] using the methodology derived by Ponton and Rawlings $[\mathbf{9}, \mathbf{1 0}]$. McColm identified various indentation techniques to determine the hardness of a variety of ceramics [11]. Strengthening of ceramics through dislocation generation by various mechanical means was conducted by Mitcjell [12], Castaing and Mazumder [13] and Rabier [14]. $\mathrm{CO}_{2}$ laser treatment of $\mathrm{Si}_{3} \mathrm{~N}_{4}$ ceramics in particular was presented in the work of Mohanty and Mazumder [15], showing enhancement of the flexural strength of the tested ceramic. Ahn et al. [16] used the 
indentation method to investigate the residual stresses in machined ceramics using an X-ray diffraction technique. Several other investigations also used various indentation methods for determining the $K_{1 c}$ of hard, brittle materials, using empirical equations applicable for radial median and Palmqvist crack systems, as well as the influence of the ceramic's grain size on the $K_{1 c}$ and elastic/plastic damage from the indentation method [17-38]. The British standard (ISO 6507-1) [39] demonstrates the techniques that are required to be complied with during the Vickers indentation tests. Complying with the regulations ensured that the tests conducted on the ceramics were valid. Moreover, other investigators further demonstrated the use of a more empirical equation, further illustrated in this paper, and the accuracy and validation of the equation, as well as the machine accuracy of various indentation techniques $[\mathbf{4 0 - 4 8}]$.

The $K_{1 c}$ is a very important property of any material. This is especially so for ceramics, owing to their brittle nature. Materials with high $K_{1 c}$ are much softer and more ductile. Those types of material can resist cracks at relatively higher stress levels and loading [9-13]. Materials with low $K_{1 c}$, such as most ceramics, are much harder and more brittle and allow crack propagation at lower stresses and loading. Unlike with metals, it is difficult for dislocations to propagate with ceramics, which makes them brittle [14-16]. Ceramics also do not yield mechanically as well as metals, which leads to a much lower resistance to fracture. Ceramics, in comparison with metals and metal alloys, have a low $K_{1 c}$; thus, it would be an advantage if the $K_{1 c}$ of ceramics could be improved. This could open new avenues for ceramics to be applicable in high-demanding applications where metals and metal alloys fail owing to their relatively low thermal resistance, coefficient of friction, wear rate, and hardness. This study investigated the use of empirical equations from the literature to calculate the $K_{1 c}$ of a $\mathrm{ZrO}_{2}$ engineering ceramic and observed the effects thereon of fibre laser radiation to effect surface treatment.

In comparison with a $\mathrm{CO}_{2}$ laser, the fibre laser has a much shorter wavelength, and so it would be interesting to investigate further the effect of shortwavelength radiation on the surface properties of a $\mathrm{ZrO}_{2}$ engineering ceramic. In addition, although the $\mathrm{Nd}$ :YAG laser wavelength is in the same region as that of the fibre laser, the Nd:YAG laser cannot be operated stably in the continuous-wave (CW) mode, which is required to minimize the thermal shock induced in a ceramic. As one can see, this work is timely, as minimal research has been conducted into employing fibre lasers for the surface treatment of materials, particularly engineering ceramics.

$K_{1 c}$ is a measure of a material's resistance to fracture or crack propagation. It is the plane strain fracture toughness. Materials with high $K_{1 c}$ are much softer and more ductile. Those types of material are resistant to crack generation when exposed to high stresses and loading. The measurement of $K_{1 c}$ was carried out using the Vickers indentation method, which calibrates the hardness of the material and induces a crack. The measured hardness and crack lengths were then placed into empirical equations to calculate the material's $K_{1 c}$ after and prior to the fibre laser surface treatment. The $K_{1 c}$ of engineering materials can be determined using various different techniques.

\section{BACKGROUND TO DETERMINE THE $K_{1 c}$ OF CERAMICS}

\subsection{Vickers indentation technique}

Single-edge notched beam (SENB), chevron notched beam (CVNB), and double-cantilever beam (DCB), as well as the Vickers indentation method, are all conventionally employed for industrial applications. The Vickers indentation test can be used to determine the $K_{1 c}$ of ceramics and glasses from empirical relationships, as demonstrated in references [8] to [17]. Advantages of the Vickers hardness test are the costeffectiveness and ease of set-up, and it is one of the simplest and least time-consuming in comparison with the other techniques available to determine the $K_{1 c}$ of ceramics. The Vickers indentation test method is less responsive in comparison with other techniques, but minimum preparation is required, with quick and cost-effective set-up and use. There are disadvantages to the Vickers indentation test, such as the lack of accuracy to measure the length of the cracks, which influences the final $K_{1 c}$ value $[\mathbf{9}, \mathbf{1 0}]$, the diversity of the use of the indentation equations, and its accuracy. The crack lengths are visualized after the test has been conducted by means of optical microscopy. Change in the $K_{1 c}$ has an influence on the material's functionality or the diversity of its applications. Improving the $K_{1 c}$ of a material can enhance its functional capabilities, such as longer functional life or improved performance under higher cyclic and mechanical loading, particularly for demanding applications where engineering ceramics are applicable. This paper illustrates a method to determine the $K_{1 c}$ by using the Vickers indentation method for the laser-treated, cold isostatic pressed (CIP) $\mathrm{ZrO}_{2}$ ceramics. The test samples were investigated for their near surface hardness, generated crack profiles, and the surface finish, from the diamond indentations prior to and after the laser treatment.

$K_{1 c}$ can be determined using the Vickers indentation technique, which measures the hardness of the material by punching an indentation, with the aid of a diamond indenter, to produce a crack in the 
material surface $[\mathbf{9}, 10,18]$. Measured hardness and the crack lengths are then placed into an empirical equation to calculate the material's $K_{1 c}[\mathbf{9 - 1 3}, \mathbf{1 9}$. The results from the Vickers indentation test can then be applicable to the empirical equations that were derived by Ponton $[\mathbf{9}, \mathbf{1 0}]$, Chicot [18], and Liang et al. [20]. The equations derived by Ponton et al. $[\mathbf{9}, \mathbf{1 0}]$ originate from various other authors [21-31]. However, they are modified and applied specifically to hard and brittle materials, such as ceramics and glass $[9,10]$. The equations have a geometrical relationship with various ceramics. Different ceramics have various equations applicable to calculate their $K_{1 c}$. Preparation of the samples involves polishing in order to create a reflective surface plane (this would mean that the surface has been well polished) $[\mathbf{9}, \mathbf{1 0}, \mathbf{3 2}, \mathbf{3 3}]$ prior to the Vickers indentation process. There are still constraints with the Vickers indentation techniques, as reported by Gong [34], compared with the more conventional techniques applied, such as the SENB and double-torsion (DT) methods, as mentioned elsewhere [17, 35-37]. The constraints are: (a) the dependence of the crack geometry on the applied indentation load and the properties of the material; (b) indentation deformation (non-uniform fracture progression or rapid fracture growth), such as lateral cracking; and (c) unsuitable consideration of the effect of Young's modulus and the material hardness [17].

The procedure and steps necessary to produce a genuine Vickers indentation test result and genuinely valid $K_{1 c}$ values are:

1. Each indentation must be performed at a sufficient distance from another. This will prevent the formed cracks interconnecting and bridging with the other diamond indentations created on the ceramic surface $[\mathbf{3 8}, \mathbf{3 9}]$.

2. A minimum load of $50 \mathrm{~N}$ must be used and is recommended because the ceramic materials are of sufficient hardness to require enough loading to produce an indentation.

3. It is ideal to coat the test surface with gold so that the performed indentations are visible. Postindentation coating may affect the crack tip and give an inaccurate reading.

4. The test samples should be near to $20 \mathrm{c}$ in thickness and have minimum porosity. The author also stated that the adjacent indentations should be no closer than $4 c$.

\section{PROPAGATION OF THE CRACK GEOMETRY DURING THE VICKERS INDENTATION TEST}

Liang et al. [20] followed an investigation into the $K_{1 c}$ of ceramics using the indentation method. He also used several equations by various authors, as listed in reference [20]. It was stated by Liang et al. that equations differ as the crack geometry changes (from Palmqvist to median half-penny cracks). He introduced a new equation, stated elsewhere [20], which was said to be more universal than previous work. However, in order for the formula to be used, it had to be manipulated sufficiently. Ponton and Rawling's $[9,10]$ formula, in comparison, was much simplified and was easy to apply. Chicot [18] conducted further investigation by applying two other equations to produce results using materials such as tungsten carbide (nickel phosphorus-treated) and pure silicon. He used the concept of a median half-penny crack and a Palmqvist crack system to determine the most applicable equation [18]. It was stated that high indenter loads produce a median half-penny crack within the material that is on the edges of the diamond indentation (footprint produced). This type of crack will always remain connected. A Palmqvist crack is produced during low indenter loading and is of a smaller scale in comparison. The Palmqvist crack will always appear in the initial stage of the crack generation during the indentation process; then, a median half-penny crack is produced once the impact of the indenter is exerted. It can be assumed that a median half-penny crack may be the result, as the ceramics are of high hardness, indicating that high indenter loads are required in order to induce visible and measurable diamond footprints.

Orange et al. [35] investigated the $K_{1 c}$ of $\mathrm{Al}_{2} \mathrm{O}_{3}-\mathrm{ZrO}_{2}$ ceramic by comparing the notched beam and the Vickers indentation techniques. Cracking behaviour was observed as Palmqvist and median half-penny crack geometries were found. Low indentation loading produced Palmqvist cracks, and, with increasing loading, median half-penny cracks were found. High micro cracking was also found with the Vickers indentation technique when fine grain size $(0-3 \mu \mathrm{m})$ ceramics were tested, and, with increasing grain size $(0-5 \mu \mathrm{m})$, the micro cracking was reduced. With the notched-beam technique, a higher $K_{1 c}$ value was achieved with increasing grain size [35]. This means that the ceramics with larger grain boundaries have a higher $K_{1 c}$ value and higher resistance to fracture. From the work of Orange et al. [35], it can be gathered that the notched-beam indentation technique produced better results than the Vickers indentation method, although the reasons behind this were not well justified.

Median half-penny-shaped cracks occur when high indentation loads are applied [19, 32, 40]. The profile of a median half-penny-shaped crack is illustrated in Fig. 1(a). It can be predicted that the outcome for most of the crack profiles in this study would be of median half-penny shape. For cracks that are of median half-penny shape, the applicable 


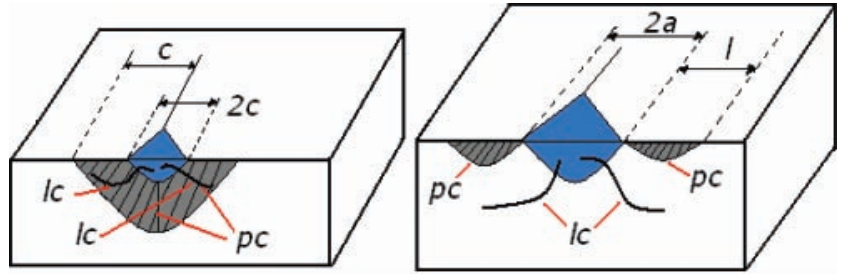

(a)

(b)

Fig. 1 Schematic diagram of (a) median half-penny crack and (b) Palmqvist crack system, where: $l$ is the surface crack length; $2 c$ or $2 a$ is the length of the diamond indent; $c$ is the centre of the diamond to the end of the crack tip; $P c$ is the load impact; and $l c$ is an interior crack

equations differ (see equations (1) to (15)) $[\mathbf{1 2}, 13]$. The indention load at which the median half-penny crack occurs for most ceramics is $3 \mathrm{~N}$ [19]; this was lower than the loads applied for this investigation. Therefore, it would be reasonable to assume that the generated cracks would always be of a half-penny median type crack profile. This indicated that only equations particularly applicable for median halfpenny cracks should be utilized for this study in order to determine the $K_{1 c}$. Figure 1(b) illustrates a profile of a Palmqvist crack, which tends to occur at low indentation loads $[\mathbf{1 9}, \mathbf{4 0}]$. A Palmqvist crack is part of the median half-penny crack system because, when a load above $3 \mathrm{~N}$ is applied, the indenter 'pop in' occurs, and the already produced Palmqvist crack further develops into a median half-penny crack [19, 40]. These cracks are shallow and lie on the axis of the indenter, as there would be a small extension at the edge of the diamond indenter [40]. Indentation loads of up to $50 \mathrm{~N}$ were used for this work, and so it is likely that a Palmqvist crack will occur, leading to a half-penny median crack geometry.

\section{SELECTION OF EQUATIONS FOR CALCULATING THE $K_{1 c}$}

Equations for median half-penny-shaped cracks were used for high indenter load applications. One equation was selected to calculate the $K_{1 c}$ value for the treated and as-received samples through application of the equation to the real experimental values. The equations were derived with the materials' geometrical values, which were obtained by experimental means for ceramics and glass $[\mathbf{9}, \mathbf{1 0}]$. Equations (1) to (15) were mentioned in the literature to be applicable for ceramics and glass-type materials; however, no such equation was defined as applicable for a certain ceramic material type; hence, the suitability of applying the various equations to the $\mathrm{ZrO}_{2}$ was not particularly defined. This is why it was required that an investigation be carried out in order to determine the most suitable equation for this study. There were ten equations selected in this study, from various equations discussed in references [9], [10], and [17], to determine first the $K_{1 c}$ of the asreceived surfaces of the $\mathrm{ZrO}_{2}$ and then the lasertreated surfaces. The selected equations applicable to calculate the $K_{1 c}$, using the Vickers indentation methods, are [9]:

$$
\begin{aligned}
& K_{1 c}=0.0101 P /\left(\operatorname{ac}^{1 / 2}\right) \quad[38] \\
& K_{1 c}=0.0515 P / c^{3 / 2} \quad[41] \\
& \boldsymbol{K}_{\mathbf{1 c}}=0.079\left(P / a^{3 / 2}\right) \log (4.5 a / c), \\
& \text { for } 0.5 \leqslant c / a<4.5 \quad[\mathbf{2 8}] \\
& K_{1 c}=0.0824 P / c^{3 / 2} \\
& K_{1 c}=0.4636\left(P / a^{3 / 2}\right)(E / H v)^{2 / 5}\left(10^{\mathrm{F}}\right) \\
& K_{1 c}=0.0141\left(P / a^{3 / 2}\right)(E / H v) 2 / 5 \log \left(8.4^{a} / c\right) \\
& K_{1 c}=0.0134(E / H V)^{1 / 2}\left(P / c^{3 / 2}\right) \\
& K_{1 c}=0.0330(E / H v)^{2 / 5}\left(P / c^{3 / 2}\right) \\
& \text { for } c / a \geqslant \approx 2.5 \quad[28] \\
& K_{1 c}=0.0363(E / H V)^{2 / 5}\left(P / a^{1 / 5}\right)(a / c)^{1.56} \quad[42] \\
& K_{1 c}=0.016(E / H v)^{1 / 2}\left(P / c^{3 / 2}\right) \\
& K_{1 c}=0.0232[f(E / H v)] P /\left(a c^{1 / 2}\right)
\end{aligned}
$$

where $F=f[\log (\mathrm{c} / \mathrm{a})]$ and is determined by the data fitting

$$
\begin{aligned}
& \text { for } c / a \leqslant \approx 2.8 \quad[\mathbf{4 7}] \\
& K_{1 c}=0.417[f(E / H v)] P /\left(a^{0.42} \mathrm{c}^{1.08}\right)
\end{aligned}
$$

where $F=f[\log (\mathrm{c} / \mathrm{a})]$ and is determined by the data fitting

$$
\begin{aligned}
& \text { for } c / a \geqslant \approx 2.8 \quad[47] \\
& K_{1 c}=\operatorname{0.095}(E / H v)^{2 / 3}\left(P / c^{3 / 2}\right) \\
& K_{1 c}=\operatorname{0.022}(E / H V)^{2 / 3}\left(P / c^{3 / 2}\right) \\
& K_{1 c}=\operatorname{0.035}(E / H v)^{1 / 4}\left(P / c^{3 / 2}\right)
\end{aligned}
$$


Ponton and Rawlings [10] state that the equation given by Kelly et al. [31] suggested that equation (10) has an accuracy of 30-40 per cent for ceramics that are well behaved in their indentation response. However, it is first required that the propagation of the crack geometry is understood from performing the Vickers indentation test on the as-received $\mathrm{ZrO}_{2}$ ceramics, as further justified in this paper. It is not made clear as to why this equation was particularly used for the ceramic. It was, therefore, required that some of the relevant equations were applied to the tested values from this experiment to determine what sort of results are obtained. A hardness test was performed on the $\mathrm{ZrO}_{2}$, assuming that the resulting cracks were of half-penny median type (as a result of applying a sufficient indentation load). Ten equations were employed, as previously stated, to establish which particular equation type produces the $K_{1 c}$ value that is the nearest to the known value for the asreceived $\mathrm{ZrO}_{2}$ ceramics, which is normally between 8 and $12 \mathrm{MPa} \mathrm{m}^{1 / 2}$.

\section{EXPERIMENTAL METHODOLOGY}

\subsection{Material details}

The material used for the experiment was CIP $\mathrm{ZrO}_{2}$, with 95 per cent $\mathrm{ZrO}_{2}$ and 5 per cent yttria (Tensky International Company Ltd). Each test piece was obtained in a bulk of $10 \times 10 \times 50 \mathrm{~mm}^{3}$, with a surface roughness of $1.58 \mu \mathrm{m}$ (as received from the manufacturer). This was to reduce the laser beam reflection, as the well-polished, shinier surfaces of the ceramic would reduce beam absorption. The experiments were conducted in ambient conditions at a known temperature $\left(20^{\circ} \mathrm{C}\right)$. All surfaces of the $\mathrm{ZrO}_{2}$ to be treated were marked with black ink prior to the laser treatment to enhance the absorption and allow the laser beam to penetrate further into the surface.

\subsection{Fibre laser treatment}

A $200 \mathrm{~W}$ fibre laser (SPI Ltd) was used in this work, emitting a wavelength of $1.075 \mu \mathrm{m}$ in the continuouswave (CW) mode. Trials ranged from 75 to $150 \mathrm{~W}$ by varying the traverse speed for the initial experiments, to find that a traverse speed of $100 \mathrm{~mm} / \mathrm{min}$ was an ideal constant to maintain for all trials, with only the laser power changing. All speeds were therefore kept to $100 \mathrm{~mm} / \mathrm{min}$ for the main set of experiments presented in Fig. 2 and Table 1. Trials below $75 \mathrm{~W}$ for the $\mathrm{ZrO}_{2}$ at $100 \mathrm{~mm} / \mathrm{min}$ showed no evidence of any influence on the $\mathrm{ZrO}_{2}$. Focal position was kept to $20 \mathrm{~mm}$ above the workpiece to obtain a $3 \mathrm{~mm}$ spot size for all trials. The processing gas used was compressed air at a flow rate of $25 \mathrm{l} / \mathrm{min}$. Programming of the laser was conducted using SPI software that

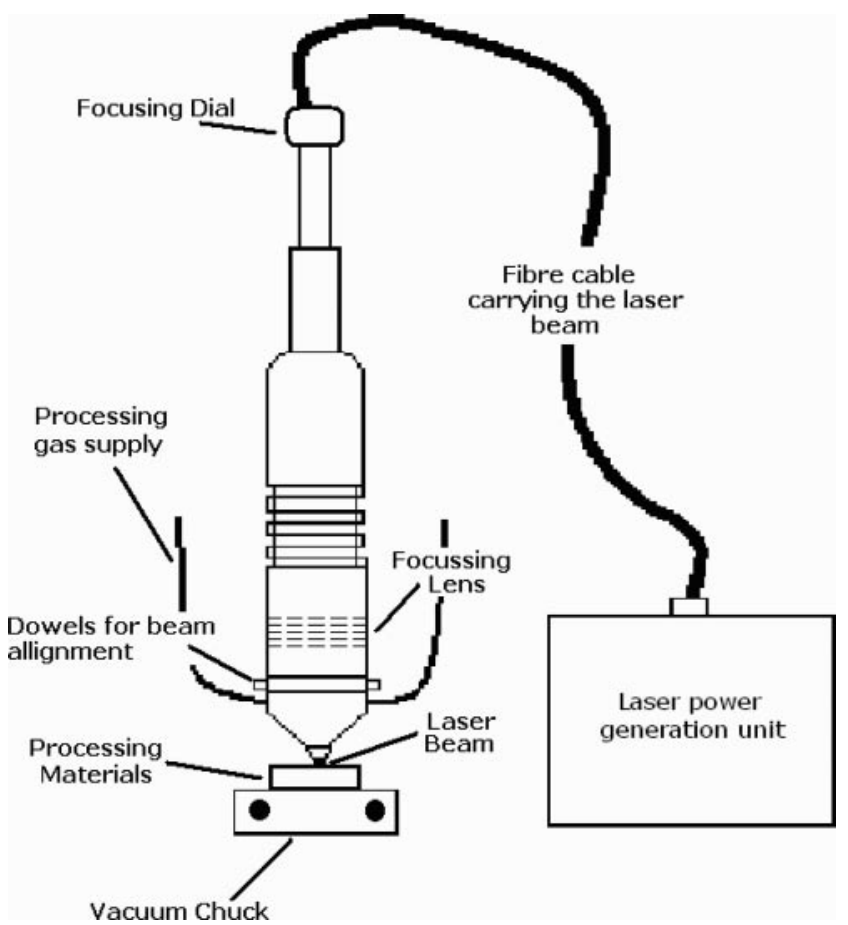

Fig. 2 Schematic diagram of the experimental set-up of the fibre laser surface treatment of the $\mathrm{ZrO}_{2}$

Table 1 Parameters used for the fibre laser treatment of the $\mathrm{ZrO}_{2}$

\begin{tabular}{|c|c|c|c|}
\hline Trial no. & $\begin{array}{l}\text { Power } \\
\text { (W) }\end{array}$ & $\begin{array}{l}\text { Power densities } \\
\left(\mathrm{W} / \mathrm{mm}^{2}\right)\end{array}$ & Comments \\
\hline 1 & 75 & 2083.33 & no visual effect \\
\hline 2 & 100 & 2777.77 & small change in colour \\
\hline 3 & 125 & 4372.22 & small cracks apparent \\
\hline 4 & 130 & 3611.11 & small cracks on the edges \\
\hline 5 & 150 & 4166.65 & large crack apparent \\
\hline 6 & 137.5 & 3819.44 & crack-free \\
\hline 7 & 143.25 & 3779.16 & crack-free \\
\hline 8 & 150 & 4166.66 & apparent cracks \\
\hline
\end{tabular}

integrated with the laser machine. A $50 \mathrm{~mm}$ line was programmed using numerical control (NC) programming as a potential beam path that was transferred by .dxf file. The nozzle indicated in Fig. 2 was removed for all experiments.

\subsection{Hardness indentation test and background of the Vickers indentation technique}

An indenter of a specific shape, made from a diamond, was used to indent the surface of the $\mathrm{ZrO}_{2}$ under investigation $[\mathbf{8}-\mathbf{1 9}, \mathbf{3 5}, \mathbf{4 0}]$. The diamond was initially pressed on to the as-received surface, and the load was then released. A diamond indentation was thus created on the surface, and its size was then measured. Thereafter, the surface area of the indentation was placed into equation (16) to calculate the hardness value: 


$$
H v=2 P \sin [\theta / 2] / D^{2}=1.8544 P / D^{2}
$$

where $P$ is the load applied $(\mathrm{kg}) ; D$ is the average diagonal size of the indentation, in $\mathrm{mm}$; and $\theta$ is the angle between the opposite faces of the diamond indenter, being $136^{\circ}$ with less than $\pm 1^{\circ}$ of tolerance. Indentation loads of 5,20 , and $30 \mathrm{~kg}$ were applied. The indented surface and the resulting crack lengths were measured using the inbuilt optical microscope of the Vickers indenter (Armstrong Engineers Ltd). This method was then implemented for the surfaces of the fibre laser-treated $\mathrm{ZrO}_{2}$. The test samples were placed under the macro indenter and were initially viewed using the built-in microscope to adjust the distance between the surface of the workpiece and the diamond indenter. This maintained a sufficient distance during each indentation and allowed a standardized testing method that complies with ISO 6507-1 [39].

\subsection{Measurement of the crack lengths}

Crack lengths generated by the Vickers diamond indentation test, as presented in Fig.3(a), were measured using a contact-less, coordinate measuring machine (CMM), Flash 200. The ceramic samples were placed under a traversing lens of the optical microscope. The lens traverses in the $y$-direction and, to adjust the magnification, it is also able to move in the $z$-direction. Motion in the $y$-direction is provided by the bed on which the test-piece is mounted for analysis of the surface. The image appears on the screen as the optical lens traverses above the surface of the test-piece. The diamond indentations and the resulting crack lengths were measured by moving the lever in the $x, y$-directions and selecting a starting point on the screen where the crack ends (crack tip) and stopping on the symmetrical side of the other (symmetrical) crack tip, which produced a measurement in both the $x$ - and $y$ directions.

\subsection{Calculation of the fracture toughness $\left(K_{1 c}\right)$}

The initial investigation used 15 equations to determine which equation type was best suited for calculating the $K_{1 c}[\mathbf{9}, \mathbf{1 0}]$. The as-received surfaces of the $\mathrm{ZrO}_{2}$ were first tested for their hardness. Fifty indentations were produced on one side of the particular surface of the $\mathrm{ZrO}_{2}$ ceramics from various test samples. Calibrated hardness was then recorded, and a mean average was measured of the as-received surfaces. Each indentation and its crack lengths were then viewed at microscopic level with the aid of the optical microscope, to observe the surface morphology. The crack lengths were measured using the Flash $200 \mathrm{CMM}$, and crack geometry was observed by a three-dimensional surface topography using whitelight interferometry (Alicona Ltd, Infinite focus, IFM 2.15). The crack lengths produced by the indentations were then placed into the various $K_{1 c}$ equations with the measured average hardness. Cracking geometries were then observed in order to confirm that the cracks generated by the diamond indentation at $5 \mathrm{~kg}$ were of median half-penny crack profile. This ensured that equations (1) to (15) used for the median half-penny crack profile were correct. Figures 4 and 5 present an example of a typical surface profile produced from the Vickers diamond indentation using $5 \mathrm{~kg}$ (see Fig. 4) and $20 \mathrm{~kg}$ (see Fig. 5) loads. Both showed evidence of median half-penny-type crack profiles where an indenter 'pop-in', indicated in Figs 4 and 5, was exerted, and then a linear crack was produced. A Palmqvist crack profile, which tends to occur with lower indentation loads, had occurred (as indicated from the indenter 'pop-in') already in this crack geometry. The concept was more present with higher indentation loading, as presented in Fig. 5.

The equations used for this study were for halfpenny median cracks. It was found that the cracks produced from the Vickers indentation test were halfpenny median type, and so other equations illustrated for Palmqvist cracks were not used. Equations (1) to (10), as presented in Table 2, were used to

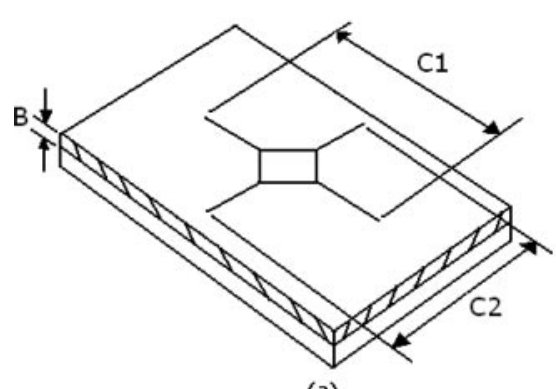

(a)

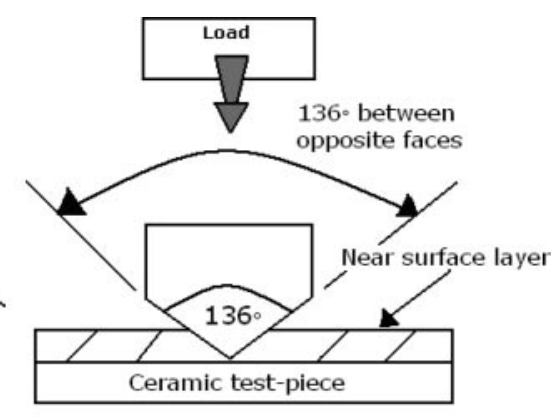

(b)

Fig. 3 Schematic diagram of a Vickers diamond indentation with (a) propagation of the cracks and (b) the concept of diamond indentation employed 


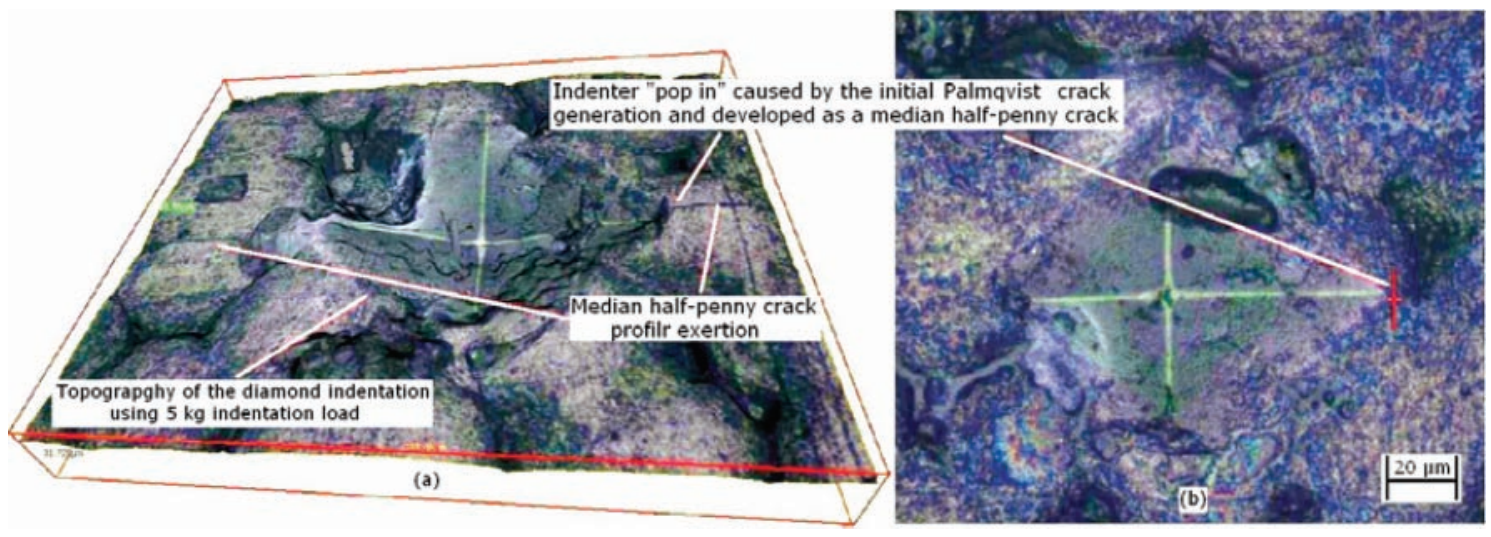

Fig. 4 Topography of the Vickers diamond indentation of the as-received surface of the $\mathrm{ZrO}_{2}$ ceramic produced by a $5 \mathrm{~kg}$ load, illustrating a median half-penny crack geometry

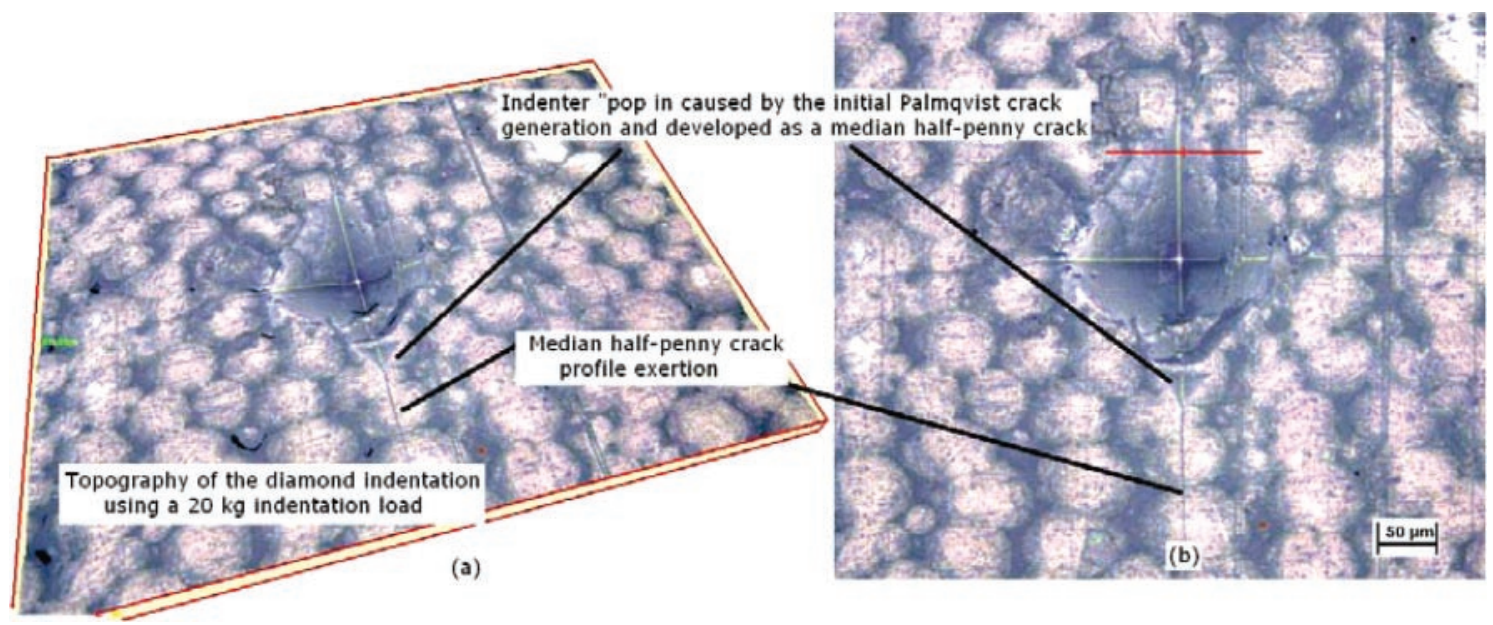

Fig. 5 Topography of the Vickers diamond indentation of the as-received surface of the $\mathrm{ZrO}_{2}$ produced by a $20 \mathrm{~kg}$ load, illustrating a median half-penny crack geometry

Table 2 Ten equations used to calculate the $K_{1 c}$ for the as-received surface of the $\mathrm{ZrO}_{2}$

\begin{tabular}{lll}
\hline $\begin{array}{l}\text { Equation } \\
\text { no. }\end{array}$ & Equation origin & Equation \\
\hline 1 & Lawn and Swain [38] & $K_{1 c}=0.0101 \mathrm{P} /\left(a c^{1 / 2}\right)$ \\
2 & Lawn and Fuller [41] & $K_{1 c}=0.0515 \mathrm{P} / \mathrm{c}^{3 / 2}$ \\
3 & Evans and Charles [24] & $K_{1 c}=0.0824 \mathrm{P} / \mathrm{c}^{3 / 2}$ \\
4 & Lawn et al. [25] & $K_{1 c}=0.0134(E / H v)^{1 / 2}\left(P / c^{3 / 2}\right)$ \\
5 & Niihara et al. [28] & $K_{1 c}=0.0330(E / H v)^{2 / 5}\left(P / c^{3 / 2}\right)$ \\
6 & Lankford [42] & $K_{1 c}=0.0363(E / H \nu)^{2 / 5}\left(P / a^{1.5}\right)$ \\
7 & & $(a / c)$ \\
8 & Laugier [43] & $K_{1 c}=0.095(E / H v)^{2 / 3}\left(P / c^{3 / 2}\right)$ \\
9 & Laugier [43] & $K_{1 c}=0.022(E / H \nu)^{2 / 3}\left(P / c^{3 / 2}\right)$ \\
10 & Tanaka [44] & $K_{1 c}=0.035(E / H v)^{1 / 4}\left(P / c^{3 / 2}\right)$ \\
& Anstis et al. [27] & $K_{1 c}=0.016(E / H \nu)^{1 / 2}\left(P / c^{3 / 2}\right)$ \\
\hline
\end{tabular}

calculate the $K_{1 c}$ value for the as-received surface of the tested $\mathrm{ZrO}_{2}$. The results have been tabulated and are presented in Table 3 . The equations were set up using Microsoft Excel, which made it easy to input parameters from the full equation. These values were
Table $3 K_{1 c}$ value obtained from ten equations for the as-received $\mathrm{ZrO}_{2}$

\begin{tabular}{cll}
\hline $\begin{array}{l}\text { Average } K_{1 c} \\
\left.(\mathrm{MPa} \mathrm{m})^{1 / 2}\right)\end{array}$ & $\begin{array}{l}\text { Percentage accuracy } \\
\left(K_{1 c} \text { value within range }\right)\end{array}$ & Status \\
\hline 0.90 & 0 & Unacceptable \\
3.25 & 0 & Under \\
5.20 & 0 & Under \\
28.70 & 0 & Unacceptable \\
683.64 & 0 & Unacceptable \\
783.93 & 0 & Unacceptable \\
2024.98 & 0 & Unacceptable \\
759.60 & 0 & Unacceptable \\
1208.44 & 0 & Unacceptable \\
12.66 & 42 & Acceptable \\
\hline
\end{tabular}

hardness, crack length, Vickers indention load, and Young's modulus. It can be seen that all the values, which range between 8 and $12 \mathrm{MPa} \mathrm{m}^{1 / 2}$ for the $\mathrm{ZrO}_{2}$, allow the equation to be accurate and useable for calculating the $K_{1 c}$ for the laser-treated and the asreceived surfaces of the $\mathrm{ZrO}_{2}$. 
$P=$ load (kg), $N=$ load in Newton's (N), $c=$ average flaw size, $a=2 c, m=$ length in metres, $H v=$ Vickers material hardness value, $E=$ Young's modulus. (Young's modulus for all untreated samples of the $\mathrm{ZrO}_{2}$ was kept to $210 \mathrm{GPa} \mathrm{m}^{1 / 2}$.) For all tested samples, the indentation loads were 5 and $30 \mathrm{~kg}$, and $E$ (Young's modulus) was $210 \mathrm{GPa} \mathrm{m}^{1 / 2}$ for the $\mathrm{ZrO}_{2}$. The range (required for equation accuracy) is 8 to $12 \mathrm{MPam}^{1 / 2} \pm 0.40 \mathrm{MPam}^{1 / 2}$. The average of the $K_{1 c}$ was obtained by using values from 50 different Vickers indentation tests. This allowed more consistency in calculating the $K_{1 c}$, as values were used from a bigger pool of data.

The values obtained using the equations in Table 2 are presented in Table 3 . The literature $K_{1 c}$ value of the untreated $\mathrm{ZrO}_{2}$ is 8 to $12 \mathrm{MPam}^{1 / 2}$, and so the values that do not lie in the range given for both ceramics were not considered as acceptable, and, therefore, those equations were discarded. The $K_{1 c}$ values obtained using equation (10) were reasonable for both of the materials and lie within the desired range, and so the equation was accurate and useable. Other equations were discarded and were not taken into consideration for use. Each of the equations was set up with the aid of an Excel spreadsheet. The experimental values obtained were input into the equation, such as the indentation load, crack length created by the Vickers diamond indentations, and the measured hardness. The equation that generated the most accurate result was equation (10). The Vickers diamond indenter was applied 50 times to the asreceived surface plane of the $\mathrm{ZrO}_{2}$. Hardness values from the indentation test were recorded, and the resulting crack lengths were then measured, first to calculate the $K_{1 c}$ of the untreated surface. From this, $50 K_{1 c}$ values were obtained from one surface plane. Thereafter, an accuracy value was determined for each of the equations by taking values that were found in the range between 8 and $12 \mathrm{MPa} \mathrm{m}^{1 / 2}$. The accuracy of the equation was determined by the number of $K_{1 c}$ values (out of 50 indentations made on one surface plane) appearing within the range between 8 and $12 \mathrm{MPam}^{1 / 2}$. The $K_{1 c}$ values within this range were considered as accurate and were used to calculate the accuracy of the equations. Up to 42 per cent accuracy was found using the same equation with the as-received surface of the $\mathrm{ZrO}_{2}$. Other equations applied were discarded as they proved to be of minimal use owing to their results from this investigation. Values obtained using equation (10) were most accurate (closer to the required range for the $\mathrm{ZrO}_{2}$ ) in comparison with the other equations; consequently, this equation was used for all asreceived and laser-treated surfaces of the $\mathrm{ZrO}_{2}$ to determine the $K_{1 c}$.

The ceramic surfaces were first treated with the fibre laser. The $K_{1 c}$ values were then calculated using equation (10). The reason for changing the Young's modulus from $210 \mathrm{GPa}$ to $260 \mathrm{GPa}$ for the $\mathrm{ZrO}_{2}$ was because of the ceramics being anisotropic (meaning the Young's modulus of the material was not uniform around all orientations of the material). This may occur owing to certain manufacturing impurities and further modifications having occurred during processing of the ceramic. As the ceramic was exposed to the fibre laser beam (thermal energy), this led to the induction of further changes within the material from the induced thermal stress, indicating that the Young's modulus value for all laser-treated samples would ideally be increased when the $K_{1 c}$ was calculated. This is why the Young's modulus was changed for the fibre laser-treated samples when determining the $K_{1 c}$ of the $\mathrm{ZrO}_{2}$ engineering ceramic.

\section{RESULTS AND DISCUSSION}

\subsection{Analysis of the as-received surfaces: using a $30 \mathrm{~kg}$ indentation load}

The average surface hardness of the as-received surface was found to be $1141 \mathrm{Hv}$ for $\mathrm{ZrO}_{2}$ (see Fig. 6 and Table 4). The values provided by the manufacturer for the as-received surfaces were 800 to $1200 \mathrm{Hv}$ for $\mathrm{ZrO}_{2}$. The ceramics were manufactured using the CIP method, which may have left porosity and surface flaws in the $\mathrm{ZrO}_{2}$ in comparison with hot isostatic pressing (HIP). The highest value was $1129 \mathrm{Hv}$, and the lowest was $757 \mathrm{Hv}$, when an indentation load of $30 \mathrm{~kg}$ was applied. This fluctuation has occurred owing to several factors such as: porous structure; the ceramic's response to the diamond indentation; surface flaws and micro cracks pre-existing on the ceramic, operator; and machine accuracy in measuring the sizes and footprints of the diamond indentations. Operator accuracy depends purely on the ability of the operator to locate and measure the size of the diamond footprint through the inbuilt lens of the Vickers indentation machine. Such errors were minimized in the work herein, as the diamond footprints and the resulting crack lengths were both measured using computational means. However, the machine accuracy of $875 \mathrm{~nm}$ for a load of $5 \mathrm{~kg}$ and $1471.5 \mathrm{~nm}$ for a load of $30 \mathrm{~kg}$ must be taken into consideration when conducting the Vickers indentation test [48].

The fluctuation found in the mean hardness from the results of this study was up to 11 per cent. This, in comparison with the values for $\mathrm{ZrO}_{2}$ given in the literature, was 1 per cent higher than the \pm 10 per cent range (error) given in [13]. An error of 1 per cent between the hardness values found in this study and the literature can be excepted from being a nonconformance and may be considered to pass the 


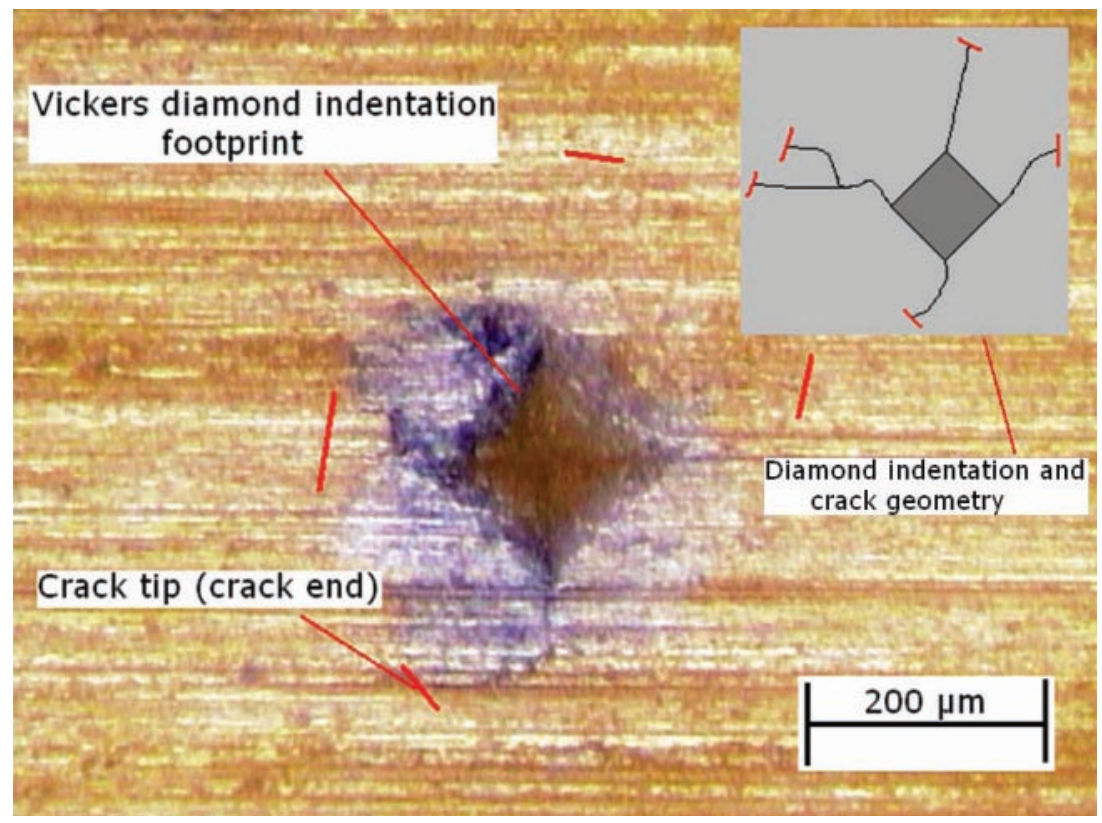

Fig. 6 Example of the as-received surface of $\mathrm{ZrO}_{2}$ indented by a $30 \mathrm{~kg}$ load (hardness $=926 \mathrm{Hv}$; crack length $=437 \mu \mathrm{m} ; K_{1 c}=6.94 \mathrm{MPa} \mathrm{m}^{1 / 2}$ )

Table 4 Summary of the results illustrating an increase or decrease in the parameters used for calculating the $K_{1 c}$ of the as-received and laser-treated surface of the $\mathrm{ZrO}_{2}$ ceramics

\begin{tabular}{|c|c|c|c|c|c|c|}
\hline & Ave & $\begin{array}{l}\text { rface hardness, } \\
\mathrm{Hv}\end{array}$ & Ave & $\begin{array}{l}\text { ace crack length } \\
\mu \mathrm{m})\end{array}$ & Aver & $\begin{array}{l}\text { ge surface } K_{1 c} \\
\text { ИPa } \mathrm{m}^{1 / 2} \text { ) }\end{array}$ \\
\hline $\begin{array}{l}\text { As-received surface using } \\
5 \mathrm{~kg} \text { load }\end{array}$ & 983 & 0 & 277 & 0 & 2.48 & 0 \\
\hline Fibre laser-treated surface & 940 & $4 \%$ lower & 177 & $38 \%$ lower & 5.62 & $56 \%$ increase \\
\hline
\end{tabular}

Note: Values for the fibre laser-treated surface were compared with the values of the as-received surface indented using a $5 \mathrm{~kg}$ load to determine the percentage rise and decrease

quality requirements if the hardness test was used for a (real-life) $\mathrm{ZrO}_{2}$ ceramic engineering component/ product.

The average crack length produced from the Vickers indentation test was $276 \mu \mathrm{m}$ for the $\mathrm{ZrO}_{2}$. Results from 50 indentations present crack lengths that range from $221 \mu \mathrm{m}$ as the lowest to $335 \mu \mathrm{m}$ as the highest. The variation from its mean value was wide owing to the micro cracks pre-existing on the $\mathrm{ZrO}_{2}$ 's surface. If the surface were well polished, the results of the crack lengths would be much lower, as the surface would be less prone to cracking after grinding and fine polishing of the $\mathrm{ZrO}_{2}$. However, a smoother surface would prevent the laser from being absorbed sufficiently into the material surface and often has the tendency to reflect more than absorb, and so the surfaces were not polished and were tested as received from the manufacturer.

From applying a $30 \mathrm{~kg}$ load, it was found that the cracks were significantly large owing to the amount of force acting on the surface area of the $\mathrm{ZrO}_{2}$. An example of such a crack profile is shown in Fig. 6. It was therefore interesting to investigate the crack lengths produced with a lower indentation load, which predictably would have a smaller effect on the end value of the $K_{1 c}$ of the $\mathrm{ZrO}_{2}$ engineering ceramic. As such, a $5 \mathrm{~kg}$ indentation load was used: owing to the force over the surface area being much lower, it produced a smaller footprint of the diamond and smaller crack lengths. This would, therefore, result in producing a lower $K_{1 c}$ value than in the literature and the manufacturer's range given for the $\mathrm{ZrO}_{2}$.

The $K_{1 c}$ values for the as-received surfaces after application of an indentation load of $30 \mathrm{~kg}$, as presented in Fig. 7, show that the values obtained complied with the values given in the literature and the values given by the manufacturer $[\mathbf{1}, \mathbf{1 3}]$. The average $K_{1 c}$ for the $\mathrm{ZrO}_{2}$ was found to be $12.7 \mathrm{MPa} \mathrm{m}^{1 / 2}$. The graph in Fig. 7 indicates that there is a significant level of fluctuation for the values above and below the mean range. 
The highest value above the mean was found to be $18.11 \mathrm{MPa} \mathrm{m}^{1 / 2}$, and the lowest value below the mean was $8.52 \mathrm{MPa} \mathrm{m}^{1 / 2}$. This has occurred owing to the following factors:

1. A change in the material hardness influences the end $K_{1 c}$ value. A change in hardness of $\pm 100 \mathrm{Hv}$ resulted in a change in the final $K_{1 c}$ value of $\pm 0.34 \mathrm{MPa} \mathrm{m}^{1 / 2}$ (according to equation (10)).

2. A change in the crack length (being the major parameter in equation (10), as used in this work) by $\pm 100 \mu \mathrm{m}$ resulted in a change in the end $K_{1 c}$ value of $\pm 6.31 \mathrm{MPa} \mathrm{m}^{1 / 2}$, if the hardness was up to $1250 \mathrm{Hv}$ as a particular input parameter in the calculation. Hence, the crack length has a bigger influence on the $K_{1 c}$ value than the hardness.

3. The surface micro cracks and porosity pre-existing on the $\mathrm{ZrO}_{2}$ surface make it prone to cracking and reduce the ceramic's resistance to fracture.

4. The response of the $\mathrm{ZrO}_{2}$ to diamond indentation in some of the areas within the $\mathrm{ZrO}_{2}$ produced fluctuating values as opposed to other areas from the viewpoint of the crack length, porosity, and the surface flaws.

The surface condition should also be considered, as the surface roughness for the $\mathrm{ZrO}_{2}$ was exceptionally high for conducting the Vickers indentation test, and this would have resulted in producing higher crack lengths that further resulted in a reduction in the $\mathrm{ZrO}_{2}$ 's $K_{1 c}$ value.

\subsection{Analysis of the as-received surfaces: using a $5 \mathrm{~kg}$ indentation load}

The hardness of the $\mathrm{ZrO}_{2}$ obtained after applying a $5 \mathrm{~kg}$ load was much lower than the hardness values obtained after applying a load of $30 \mathrm{~kg}$. This was because the $5 \mathrm{~kg}$ load applied to the material's surface area resulted in lower penetration of the diamond indentation into the $\mathrm{ZrO}_{2}$, as well as the surface area of the diamond footprint being smaller in dimension, which resulted in the generation of a lower hardness value. The average hardness value for the $\mathrm{ZrO}_{2}$ was $983 \mathrm{Hv}$, with the highest value being $1330 \mathrm{Hv}$ above the mean and the lowest being $707 \mathrm{Hv}$ below the mean. The hardness values of the $\mathrm{ZrO}_{2}$ using a $5 \mathrm{~kg}$ load agree with the hardness values provided by the manufacturer; however, they were found to be towards a bottom limit. A possible cause of this vast fluctuation in the values may have been the $\mathrm{ZrO}_{2}$ exhibiting micro cracks, porosity, and impurities on the near surface layer in comparison with the bulk hardness, which frequently produced non-uniform results.

The results showed minimal difference in the generated crack lengths for the $\mathrm{ZrO}_{2}$ obtained by applying a $5 \mathrm{~kg}$ load in comparison with the results obtained by applying a $30 \mathrm{~kg}$ load. The average crack length was $279 \mu \mathrm{m}$. Despite the indentation load and the applied force being much smaller in comparison with the $30 \mathrm{~kg}$ load, the material was still cracking in equivalent measure to the results of the trials conducted using a higher load. This clearly indicated that the surface did not exhibit a good response during the indentation test. This meant that a smoother surface finish was required for the indentation test in order to overcome this problem, so that the surface scarring and micro cracks pre-existing on the $\mathrm{ZrO}_{2}$ were minimized, and the strength of the top surface layer is further enhanced for a better indentation response. This also has the possibility of increasing the surface hardness and yet, at the same time, would reduce the resulting cracks from the Vickers diamond footprints and avoid crack bridging between the

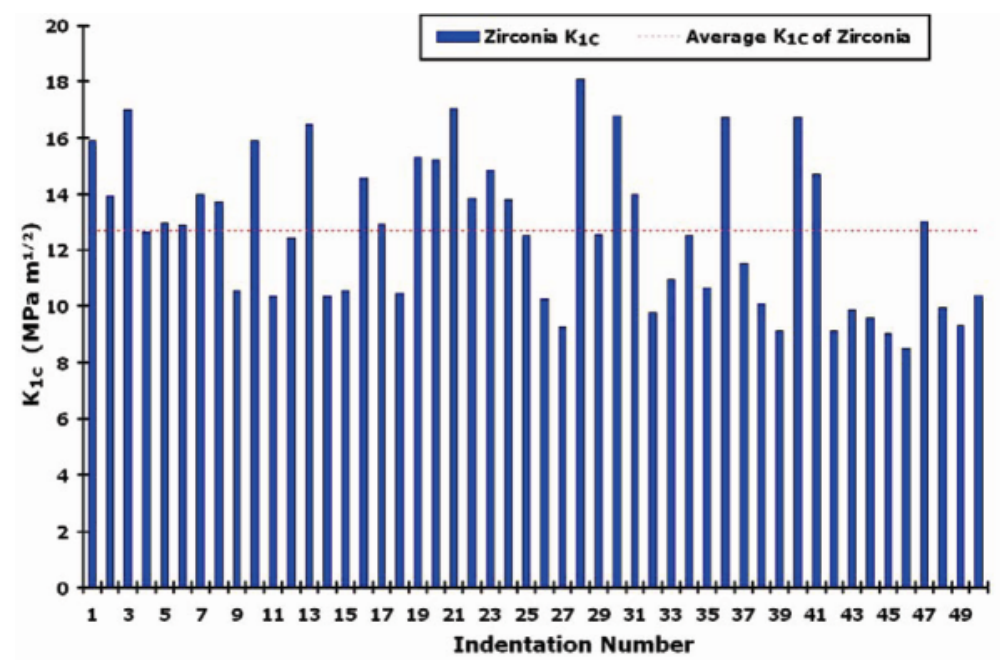

Fig. $7 K_{1 c}$ of the as-received surface of the $\mathrm{ZrO}_{2}$ after application of a $30 \mathrm{~kg}$ load 
diamond footprints and the pre-existing surface micro cracks.

Ponton and Rawlings [9] suggested that a minimum loading of $50 \mathrm{~N}$ must be pressed in order to produce a diamond indentation; the minimum loading used herein agrees with the work of Ponton and Rawlings [9]. However, the loading herein was 49.05 N, and we still see a diamond indentation, as presented in Fig. 8, with a median half-penny-shape profile. Initial experiments using lower indentation loads such as $24.5 \mathrm{~N}$ and $9.8 \mathrm{~N}$ also presented a sufficient indented footprint from the Vickers hardness test. The diamond indentation in Fig. 8 is smaller in size than the indentation created by the $30 \mathrm{~kg}$ load.
However, the average crack lengths found using a $5 \mathrm{~kg}$ indentation load were of equal size to those found with the $30 \mathrm{~kg}$ load. The difference between the average values for the two test results was 3 per cent and less when considering a larger pool of data. From this, it can be gathered that the macro hardness indentation test may be more stable at higher indentation loads than lower, particularly with hard, brittle materials such as $\mathrm{ZrO}_{2}$.

The results found for hardness herein when employing a $30 \mathrm{~kg}$ indentation load match the values provided by the manufacturer and prove that the method used for the hardness calculation and measurement of the crack lengths was valid, although the

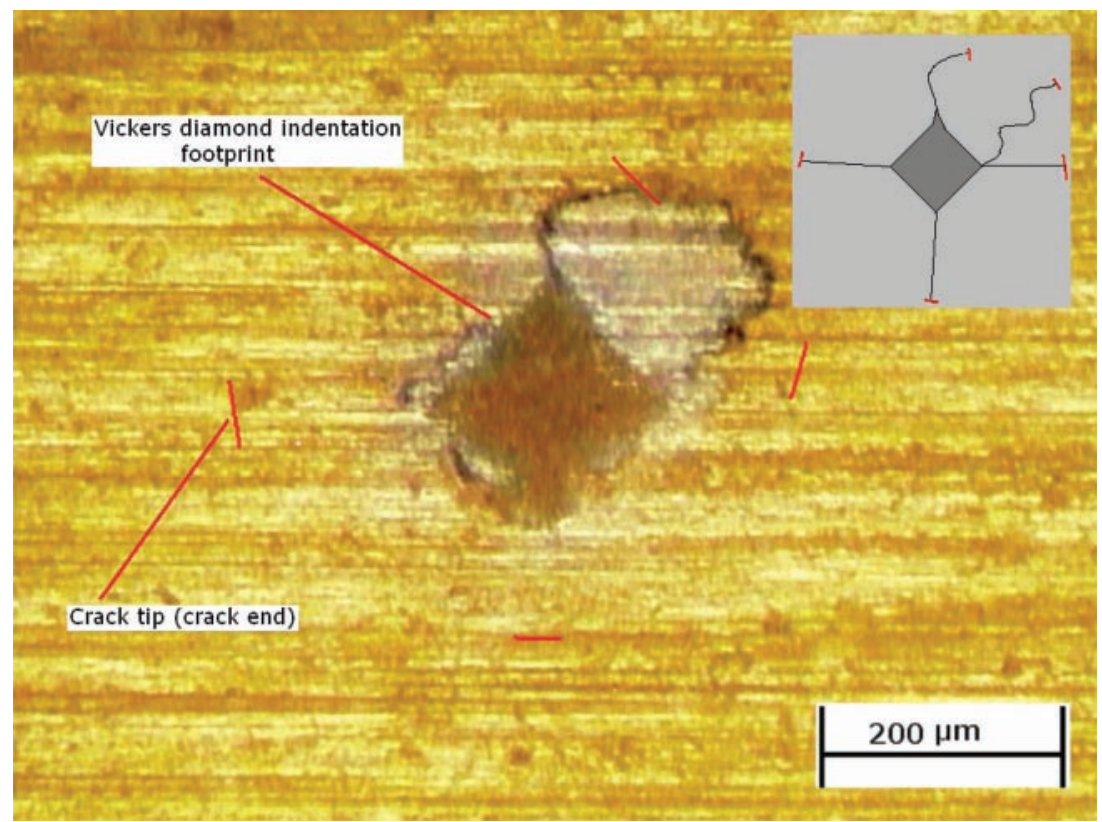

Fig. 8 Example of the as-received surface of $\mathrm{ZrO}_{2}$ indented by a $5 \mathrm{~kg}$ load (hardness $=1120 \mathrm{Hv}$; crack length $=425 \mu \mathrm{m} ; K_{1 c}=1.10 \mathrm{MPa} \mathrm{m}^{1 / 2}$ )

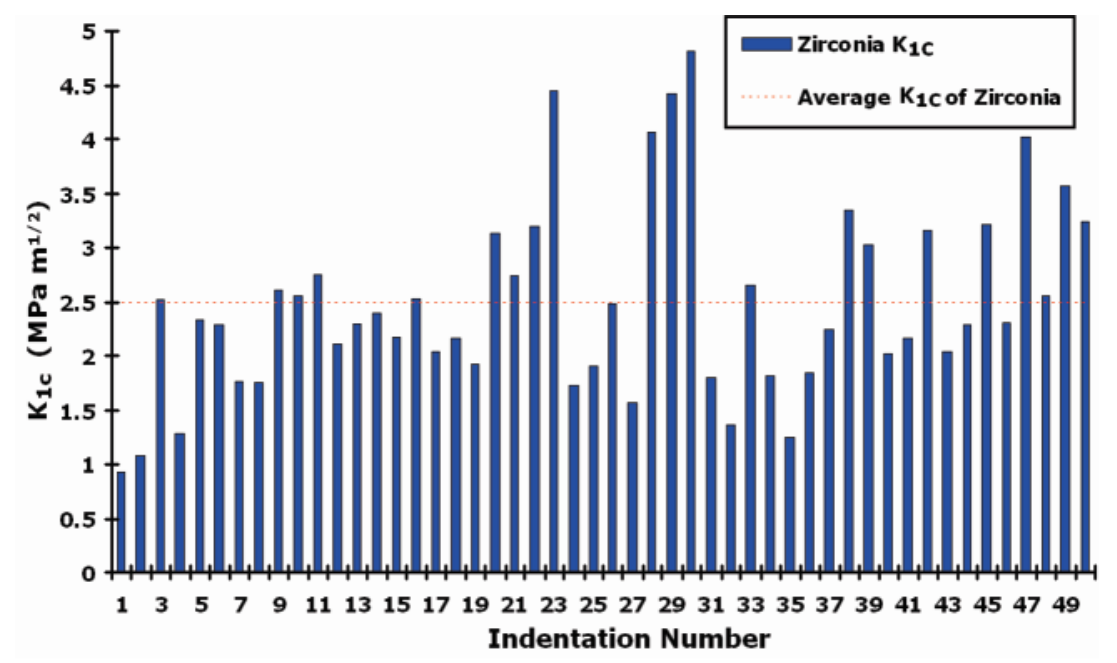

Fig. $9 K_{1 c}$ of the as-received surfaces of the $\mathrm{ZrO}_{2}$ after application of a $5 \mathrm{~kg}$ indentation load 
values for the hardness are much smaller than the values provided in the manufacturer's specification when a $5 \mathrm{~kg}$ load was used. This was owing to the fact that the indentation load was much smaller and produced smaller footprints of the diamond, which exerted lower force on the surface and reduced the end value of the $K_{1 c}$. The average $K_{1 c}$ was found to be $2.53 \mathrm{MPam}^{1 / 2}$ for the $\mathrm{ZrO}_{2}$, as presented in Fig. 9, which also shows the highest value to be $6.02 \mathrm{MPa} \mathrm{m}^{1 / 2}$ and the lowest to be $0.88 \mathrm{MPam}^{1 / 2}$. The hardness could be much higher if the surfaces were ground and polished prior to the Vickers indentation test, as previously stated. This would minimize the surface micro cracks and result in better consistency in achieving the hardness value and the resulting crack lengths. The surfaces were tested as received owing to the comparison made with the laser-treated surface, as the ground and polished surfaces would enhance the material's reflectivity of the laser beam and would minimize the laser beam absorption into the $\mathrm{ZrO}_{2}$; consequently, a compromise was required to be made.

\subsection{Analysis of the fibre laser-treated surfaces: using a $5 \mathrm{~kg}$ indentation load}

The mean hardness found was $940 \mathrm{Hv}$ on the fibre laser-treated $\mathrm{ZrO}_{2}$ surface. The highest value above the mean was $1089 \mathrm{Hv}$, and the lowest was $826 \mathrm{Hv}$. There was a 4.5 per cent difference between the average hardness values obtained from the fibre laser treatment and those obtained from the as-received surface. The fibre laser had decreased the hardness in comparison with that of the as-received surface of the $\mathrm{ZrO}_{2}$. The average crack length of the fibre-treated $\mathrm{ZrO}_{2}$ was $171 \mu \mathrm{m}$. The crack length was much reduced in comparison with the crack length of the as-received surface, which was $277 \mu \mathrm{m}$. The fibre laser-treated surfaces also had much smaller cracks in comparison with the as-received surface (see example in Fig. 10). The reduction in the surface hardness indicated that the laser surface treatment had softened the top (near) surface layer of the $\mathrm{ZrO}_{2}$. From this, it can be assumed that some degree of melting and solidification may have taken place during the laser-ceramic interaction. This would have caused a localized ductile surface to have formed, along with a change in the surface composition. Further studies are being undertaken to determine this effect.

The average $K_{1 c}$ value for the $\mathrm{ZrO}_{2}$ after the fibre laser treatment was $5.62 \mathrm{MPam}^{1 / 2}$. The highest $K_{1 c}$

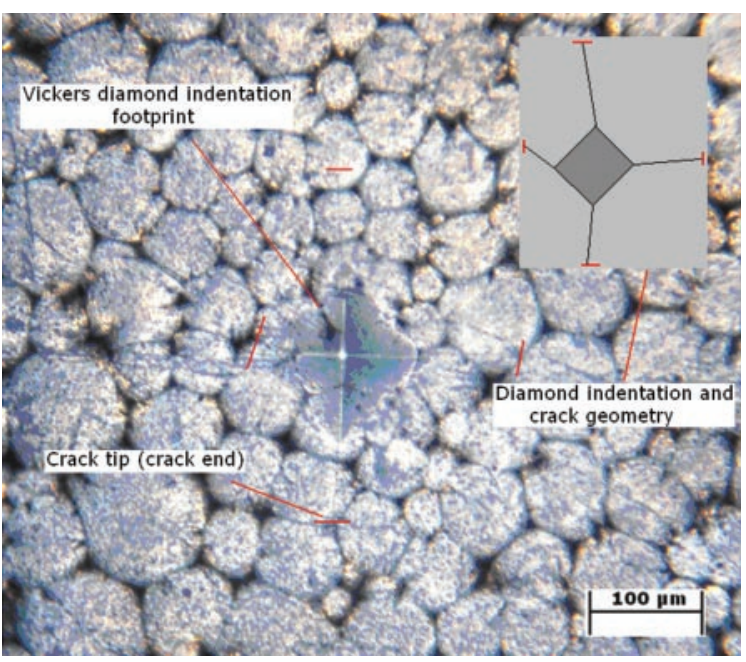

Fig. 10 Example of the fibre laser-treated surface of the $\mathrm{ZrO}_{2}$ indented by a $5 \mathrm{~kg}$ load, laser power $=150 \mathrm{~W}$, $100 \mathrm{~mm} / \mathrm{min}, 3 \mathrm{~mm}$ post size (hardness $=654 \mathrm{Hv}$; crack length $=232 \mu \mathrm{m} ; K_{1 c}=3.97 \mathrm{MPa} \mathrm{m}^{1 / 2}$ )

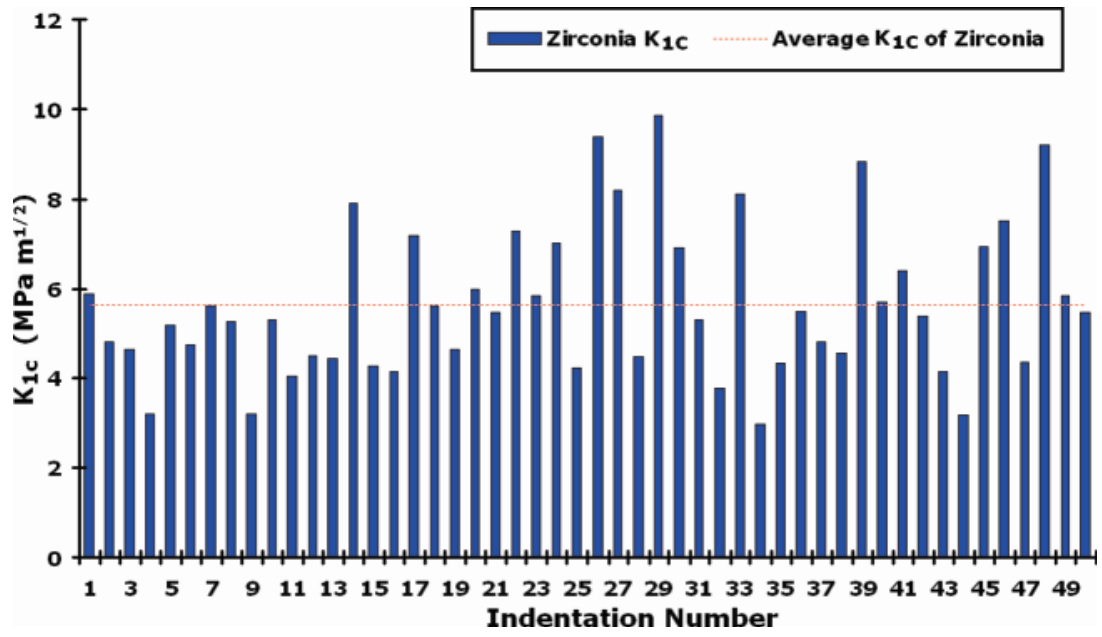

Fig. $11 K_{1 c}$ of the fibre laser-treated surfaces of $\mathrm{ZrO}_{2}$ after application of $5 \mathrm{~kg}$ indentation load 
value obtained above the mean was $9.85 \mathrm{MPa} \mathrm{m}^{1 / 2}$. The lowest value below the mean was $2.97 \mathrm{MPa} \mathrm{m}^{1 / 2}$ for the $\mathrm{ZrO}_{2}$, as presented in Fig. 11 and Table 4. The $K_{1 c}$ values for the fibre laser-treated $\mathrm{ZrO}_{2}$ surface were enhanced by 56 per cent in comparison with those of the as-received surfaces. The values in Fig. 11 fluctuate owing to the softening of the treated surface, which would have generated lower cracks during the indentation test. Those areas where $K_{1 c}$ is high indicate that the localized, near-surface layer has more resistance to crack propagation under cyclic loads or during the onset of any tensile stresses. The Young's modulus is another factor that also influenced this change in the $\mathrm{ZrO}_{2}$ 's $K_{1 c}$. The Young's modulus was increased from $210 \mathrm{GPa}$ (as-received surface) to $260 \mathrm{GPa}$ (laser-treated surface) when the $K_{1 c}$ was being determined. This was because the ratio of stress and strain was higher after the laser treatment. Owing to the way in which the Young's modulus contributing to the $K_{1 c}$ equation was used, it was likely that the influence of the Young's modulus was significant in calculating the $K_{1 c}$ values in this investigation. The end value of the $K_{1 c}$ would be slightly reduced during the calculation of the $K_{1 c}$ of the lasertreated $\mathrm{ZrO}_{2}$ in the case of the Young's modulus being kept the same for the as-received surface.

\section{CONCLUSIONS}

Empirical equations were used on the as-received surfaces of the $\mathrm{ZrO}_{2}$ to investigate the most suitable equation for calculating the $K_{1 c}$. Palmqvist cracks were produced, leading to half-penny median type cracks observed from the topographical investigation at indentation loads of 5,20 , and $30 \mathrm{~kg}$. This confirmed the use of the group of equations applied for the investigation. The results from the computational analysis showed that equation (10) $\left(K_{1 c}=0.016\right.$ $\left.(E / H v)^{1 / 2}\left(P / c^{3 / 2}\right)\right)$ by Anstis et al. [27] was the most accurate. It produced 42 per cent accuracy with the $K_{1 c}$ values that were found within the range (8 to $12 \mathrm{MPa} \mathrm{m}^{1 / 2}$ ) given in the literature and by the manufacturer of the $\mathrm{ZrO}_{2}$.

The as-received surface analysis showed that the most influential parameter in calculating the $K_{1 c}$ was crack length, as it proved that longer cracks produced by the Vickers indentation led to lower resistance for the $\mathrm{ZrO}_{2}$ to propagate a crack. Surfaces with shorter crack lengths exhibited higher resistance to indentation, which further led to an improved $K_{1 c}$ value. Hardness also influenced the $\mathrm{ZrO}_{2}$ 's $K_{1 c}$, as the results showed that surfaces with high hardness produced bigger crack lengths, which reduced the $K_{1 c}$, and lower surface hardness reduced the crack propagation. This complied with the concept of softer (ductile) surfaces being less prone to cracking.
Furthermore, the changes in the hardness demonstrated that the hardness acted as an influential parameter in changing the surface $K_{1 c}$ value of the $\mathrm{ZrO}_{2}$. The average hardness of the as-received surface was found to be $983 \mathrm{Hv}$, with the average crack length being $277 \mu \mathrm{m}$ using a $5 \mathrm{~kg}$ indentation load, which led to an average surface $K_{1 c}$ value of $2.48 \mathrm{MPa} \mathrm{m}^{1 / 2}$.

It was found that higher indentation loads produced bigger diamond footprints and generated greater crack lengths. However, the $K_{1 c}$ values were also increased with the higher load, owing to the indentation load also being an important function of the $K_{1 c}$ equation when the indentation method is employed to determine the ceramic's $K_{1 c}$. The increase in the Young's modulus had affected the $K_{1 c}$ value, owing to the ratio of stress to strain possibly increasing after the laser treatment. The values of $K_{1 c}$ for the fibre laser-treated surface would be slightly lower if stress and strain were not considered.

Comparison of the as-received surface with the fibre laser-treated surface, as presented in Table 4, showed improvement in the $K_{1 c}$ value of the top (near) surface layer of the fibre laser-treated $\mathrm{ZrO}_{2}$. The hardness was reduced by 4 per cent, which resulted in lowering of the crack lengths to 38 per cent. The average hardness found with the fibre laser-treated surface was $941 \mathrm{Hv}$, with the average crack length being $177 \mu \mathrm{m}$. This resulted in boosting the $K_{1 c}$ value to $5.62 \mathrm{MPa} \mathrm{m}^{1 / 2}$, which was 56 per cent higher in comparison with the as-received surface. This was owing to the hardness and the crack lengths produced by the Vickers indentation being lower than those of the as-received surface. From this, it was indicative that the laser treatment had softened the localized surface layer as the surface melted and solidified. Further investigations are being undertaken to elaborate this effect.

Despite the advantages, the Vickers indentation method to calculate the ceramic's $K_{1 c}$ in general comprises of many flaws, such as the results obtained from the hardness test heavily depending on the operator's ability to detect the crack lengths and the geometry. Also the ceramics geometrical response to the diamond indentation as well as the level of surface roughness of the ceramic, since a smoother surface than the used in this study would result in a higher surface strength and in fluence the hardness and the resulting crack length values. The $K_{1 c}$ results could be much more accurate if a consistent surface hardness value was obtained, along with its crack geometry, which could be found from employing other indentation techniques as well as various other methods using many other existing equations, which would also produce variation in the $K_{1 c}$ value. 


\section{REFERENCES}

1 Richardson, D. Modern ceramic engineering, third edition, 2006 (CRC Press, Taylor \& Francis Group).

2 Kawamura, $\mathbf{H}$. New perspectives in engine applications of engineering ceramics. Science of Engineering Ceramics II, International Symposium, 1999, vol. 161, pp. 9-16.

3 Mikijelj, B. and Mangels, J. SRBSN material development for automotive applications. Seventh International Symposium on Ceramic Materials and Components for Engines, 2000.

4 Mikijelj, B., Mangels, J., and Belfield, E. High contact stress applications of silicon nitride in modern diesel engines. Institution of Mechanical Engineers, Fuel Injection System Conference, London, 2002.

5 Mangels, J. A proven ceramic material for engine applications. Institution of Mechanical Engineers, Fuel Injection System Conference, London, 2006.

6 Spriggs, R. M. Applications and prospective markets for advanced technical ceramics. Key Applications of Materials, 1999, 56-57, 1-12.

7 Rödel, J., Kounga, A. N., Weissenberger-Eibl, M., Koch, D., Bierwisch, A., Rossner, W., Hoffmann, M., Danzer, R., and Schweider, G. Development of a road map for advanced ceramics: 2010-2025. J. European Ceramic Soc., 2009, 29, 1549-1560.

8 Shukla, P. P. Laser surface treatment of silicon nitride using contact-less energy beams, MSc by Research thesis, Coventry University, United Kingdom, 2007.

9 Ponton, C. B. and Rawlings, R. D. Vickers indentation fracture toughness test, Part 1 - Review of literature and formulation of standardised indentation toughness equations. Mater. Sci. Technol., 1989, 5, 865-872.

10 Ponton, C. B. and Rawlings, R. D. Vickers indentation fracture toughness test, Part 2 - Review of literature and formulation of standardised indentation toughness equations. Mater. Sci. Technol., 1989, 5, 961-976.

11 McColm, I. J. Ceramic hardness, 1990, (UK, University of Bradford, New York, Platinum Press).

12 Mitcjell, T. E. Dislocations in ceramics. Mater. Sci. Technol., 1985, 1, 944-949.

13 Castaing, J. and Veyssiere, P. Core structure dislocations in ceramics. Crystal lattice defects and amorphous materials. 1985, 12, 213-227.

14 Rabier, J. Plastic deformation and dislocations in ceramic materials. Radiation Effects and Defects in Solids. 1995, 137, 205-212.

15 Mohanty, P. S. and Mazumder, J. Solidification and microstructural evolution during laser beam- material interaction. Metall. Mater. Trans. B, 1998, 29B, 12691279.

16 Ahn, Y., Chandrasekar, S., and Farris, T. N. Determination of surface residual stress in machined ceramics using indentation fracture. J. Mfg Sci. Engng, 1996, 118, 483-489.

17 Liang, K. M., Orange, G., and Fantozzi, G. Evaluation by indentation of fracture toughness of ceramics. J. Mater. Sci., 1990, 25, 207-214.
18 Chicot, D. New development for fracture toughness determination by Vickers indentation. Mater. Sci. Technol., 2004, 20, 877-884.

19 Matsumoto, R. K. L. Evaluation of fracture toughness determination method as applied to ceria - stabilized tetragonal Zirconia polycrystal. J. Am. Ceram. Soc., 1987, 70, 366-368.

20 Liang, K. M., Orange, G., and Fantozzi, G. Crack resistance and fracture toughness of Alumina and Zirconia ceramics: Comparison of notched- beam and indentation technique. Science Ceramics 14th International Conference1988, 14, pp. 709-714.

21 Exner, H. E. The influence of sample preparation on Palmqvist's method for toughness testing of cemented carbides. Trans. Metall. Soc. AIME, 1989, 245(4), 677683.

22 Marion, R. H. In fracture mechanics applied to brittle materials. STP 678 (Ed. S. W Freiman), 1979, pp. 103-111 (ASTM , Philadelphia, PA).

23 Evans, A. G. and Wilshaw, T. R. Quasi static particle damage in brittle solids. Acta Metall., 1976, 24, 939-956.

24 Evans, A. G. and Charles, E. A. Fracture toughness determinations by indentation. J. Am. Soc., 1976, 59(7-8), 371-372.

25 Lawn, B. R., Evans, A. G., and Marshall, D. B. Elastic/ plastic indentation damage in ceramic: the median/ radial crack system. J. Am. Ceram. Soc., 1980, 63(9-10), 574-581.

26 Marshall, D. B. Failure from contact induced surface flaws. J. Am. Ceram. Soc., 1983, 66, 127-131.

27 Anstis, G. R., Chanrikul, P., Lawn, B. R., and Marshall, D. B. J. Am. Ceram. Soc.. 1981, 64, 533-538.

28 Niihara, K., Morena, R., and Hasselman. Evaluation of $K_{1 c}$ of brittle solids by the indentation method with low crack-to-indent ratios. J. Mater. Sci. Lit., 1982, 1, 13-16.

29 Tani, T., Miyamoto, Y., and Koizumi, M. Grain size dependences of Vickers microhardness and fracture toughness in $\mathrm{Al}_{2} \mathrm{O}_{3}$ and $\mathrm{Y}_{2} \mathrm{O}_{3}$ ceramics. Ceram. Int., 1986, 12(1), 33-37.

30 Hoshide, T. Grain fracture model and its application to strength evaluation in engineering ceramics. Engng Fracture Mech., 1993, 44(3), 403-408.

31 Kelly, J. R., Cohen, M. E., and Tesk, J. A. Error biases in the calculation of indentation fracture toughness for ceramics. J. Am. Ceram. Soc., 1993, 76(10), 2665-2668.

32 Li, Z., Gosh, A., Kobayashi, A. S., and Bradt, R. C. Indentation fracture toughness of sintered silicon nitride in the Palmqvist crack regime. J. Am. Ceram. Soc., 1989, 72, 904-911.

33 Strakna, T. J. and Jahanmir, S. Influence of grinding direction on Fracture strength of silicon nitride. Machining Adv. Mater., 1995, 208, 53-64.

34 Gong, J. Determining indentation toughness by incorporating true hardness into fracture mechanics equations. J. Eur. Ceram. Soc., 1998, 19, 1585-1592.

35 Orange, O., Liang, K. M., and Fantozzi, G. Crack resistance and fracture toughness of alumina and Zirconia ceramics: comparison of notched beam and indentation technique. Sci. Ceram., 1987, 14(7-9), 709-714. 
36 Glandous, J. C., Rouxl, T., and Qiu, T. Study of the Y-TZP toughness by an indentation method. Ceram. Int., 1991, 17, 129-135.

37 Fischer, H., Waindich, A., and Telle, R. Influence of preparation of ceramic SEVNB specimens on fracture toughness testing results. Dental Mater., 2006, 24, 618622.

38 Lawn, B. R. and Swain, M. V. Microfracture: beneath point indentations in brittle solids. J. Mater. Sci., 1975, 10, 113-122.

39 British Standards. Vickers hardness test - Part 2 - Verification and calibration of testing machines, 2005, Metallic Materials - ISO 6507-1.

40 Lawn, B. R. and Wilshaw, T. R. Indentation fracture: principles and application. J. Mater. Sci., 1975, 10, 10491081.

41 Lawn, B. R. and Fuller, E. R. Equilibrium penny-like cracks in indentation fracture. J. Mater. Sci., 1975, 10, 2016-2024.

42 Lankford, J. Indentation microfracture in the Palmqvist crack regime: implication for fracture toughness evaluation by the indentation method. J. Mater. Sci. Lett., 1982, 1, 493-495.

43 Laugier, M. T. The elastic/plastic indentation of ceramics. J. Mater. Sci. Lett., 1985, 4, 1539-1541.

44 Tanaka, K. Elastic/plastic indentation hardness and indentation fracture toughness: The inclusion core model. J. Mater. Sci., 1987, 22, 1501-1508.

45 Evans, A. G. Fracture mechanics applied to brittle materials. STP 678 (Ed. S. W. Freiman), 1979, pp. 112-135 (ASTM,Philadelphia, PA).

46 Blendell, J. E. PhD thesis, Massachusetts Institute of Technology, 1979.

47 Miranzo, P. and Moya, J. S. Elastic/plastic indentation in ceramics: a fracture toughness determination. Ceram. Int., 1984, 10(4), 147-152.

48 Ullner, C., Reimann, E., Kohlhoff, H., and SubaricLeitis, A. Effect and measurement of the machine compliance in the macro range of instrumented indentation test. Measurement, 2010, 43, 216-222.

\section{APPENDIX}

\section{Notation}

$a$

$c$

$D$

E

F

$\mathrm{Hv}$

$K_{1 c}$

$\mathrm{NC}$

$P$

Pc
Twice the average flaw size (2c)

Average flaw size

Average diagonal size

Young's modulus

$f[\log (c / a)]$

Hardness

Fracture toughness

Numerical control

Load (Kg)

Load impact 